\title{
Automated cell cycle and cell size measurements for single-cell gene expression studies
}

\author{
Anissa Guillemin ${ }^{1 *}$, Angélique Richard ${ }^{1}$, Sandrine Gonin-Giraud ${ }^{1}$ and Olivier Gandrillon ${ }^{1,2}$
}

\begin{abstract}
Objectives: Recent rise of single-cell studies revealed the importance of understanding the role of cell-to-cell variability, especially at the transcriptomic level. One of the numerous sources of cell-to-cell variation in gene expression is the heterogeneity in cell proliferation state. In order to identify how cell cycle and cell size influences gene expression variability at the single-cell level, we provide an universal and automatic toxic-free label method, compatible with single-cell high-throughput RT-qPCR. The method consists of isolating cells after a double-stained, analyzing their morphological parameters and performing a transcriptomic analysis on the same identified cells.

Results: This led to an unbiased gene expression analysis and could be also used for improving single-cell tracking and imaging when combined with cell isolation. As an application for this technique, we showed that cell-to-cell variability in chicken erythroid progenitors was negligibly influenced by cell size nor cell cycle.
\end{abstract}

Keywords: Cell size, Cell cycle, Gene expression, Single-cell transcriptomic

\section{Introduction}

It has been known for decades that isogenic cells can differ from each other in their molecular composition $[1,2]$. The refinement of molecular techniques together with computational approaches has recently allowed to get a quantitative view on this cell-to-cell variability. This strongly highlighted the importance of understanding the causes in such variations, leading to a recent turning point in single-cell studies [3-6].

A leading source of cell-to-cell variability can be attributed to stochastic gene expression [7-9]. Numerous factors contribute to cell-to-cell variability such as reactions involving a low-copy number of molecules especially during transcription processes $[5,7,10,11]$ or differences in the internal states of a cell population such as cellular age or cell cycle stage. In litterature, we can find

\footnotetext{
*Correspondence: anissa.guillemin@ens-lyon.fr

${ }^{1}$ Laboratoire de biologie et modélisation de la cellule. LBMC-Ecole Normale Supérieure-Lyon, Université Claude Bernard Lyon 1, Institut National de la Santé et de la Recherche Médicale: U1210-Ecole Normale Supérieure de Lyon, Centre National de la Recherche Scientifique: UMR5239, 46 Allée d'Italie, 69007 Lyon, France

Full list of author information is available at the end of the article
}

contradictory results regarding the influence of cell cycle and cell size on gene expression. Some studies argued that both of these morphological parameters affect gene expression variation [7, 12-17] whereas, others support that this impact is negligible [18-21].

Stochastic gene expression takes various biological meaning [22-24]. In a cell fate context, stochastic gene expression could drive cells into the differentiation process [25]. It has been shown that during the erythroid differentiation process, we can observe an increase in cell-to-cell variability among genes expression that may participate to the decision making process within differentiation [21].

Together, these information highlight the importance to precisely identify the sources of gene expression variability involved in these phenomena in order to understand their role, and to discard potential confounding effects.

Cell cycle variability can be identified and suppressed by fluorescent-labeling of cell cycle-specific genes, however this method requires genetical alteration of the investigated cells [26]. Other studies, based on computational approach, deconvolute the cell cycle variables in 
order to normalize their single-cell gene expression data. Most of them use cell cycle marker genes to train algorithms that can predict cell cycle stage of individual cells $[14,27,28]$. However, these genes have different function or timing according to cell type, even in a same organism [29].

In this article, we propose a more direct approach that consists in measuring morphological parameters in a high-throughput single-cell RT-qPCR study. Using a noncytotoxic double-staining technique we measured automatically cell cycle phase and cell size of every single-cell isolated from T2EC, a primary chicken erythroid progenitor cells [30]. We demonstrated that the labelling had no detectable effects at the single-cell transcriptomic level in those primary progenitors, suggesting that this technique could be an useful tool for molecular single-cell based studies.

We finally showed that in our cellular system neither cell size nor cell cycle state could be deemed responsible for the cell-to-cell variation we observed, ruling out their potential confounding effects.

\section{Main text \\ Methods \\ Cell culture}

T2EC were extracted from bone marrow of 19 days-old SPAFAS white leghorn chickens embryos (INRA, Tours, France). The composition of the culture medium has been previously described [21].

\section{Double-staining}

Cells were incubated in their initial medium for $30 \mathrm{~min}$ with CFSE (5-(and 6)-carboxyfluorescein diacetate succinimidyl ester, Life Tech.) at $5 \mu \mathrm{M}$ and Hoechst 33342 (Life Tech.) at $5 \mu \mathrm{g} / \mathrm{mL}$ at $37^{\circ} \mathrm{C}$ in a tube protected from light. After 2 washings in phosphate-buffered saline (PBS, Life Tech.), cells were loaded in the $\mathrm{C} 1$ system (Fluidigm).

\section{$R T-q P C R$ at population level}

Cell culture were washed with PBS $4 \mathrm{~h}$ after the doublestaining. Total RNA was extracted using RNeasy Mini Kit (Qiagen).

Reverse transcription assays were performed using the Superscript III First-Strand Synthesis System (Invitrogen) for $500 \mathrm{ng}$ of total RNA.

Real-time PCR was performed with SYBR Green PCR Kit (ClonTech) in the CFX96 real-time PCR system (Bio$\mathrm{rad})$. Specific primers were used to quantify the expression of genes [21].

\section{$R T-q P C R$ at single-cell level}

- From cell isolation to pre-amplification Cells were diluted with $\mathrm{C} 1$ cell suspension reagent (Fluidigm) at a concentration of $4 \times 10^{5}$ cells $/ \mathrm{mL}$. This step was followed by a cell filtration in a cellular sieve $(50 \mu \mathrm{m})$. Cells were loaded in the C1 IFC (5-10 $\mu \mathrm{m}$ trap size, Fluidigm). The $\mathrm{C} 1$ system performed the cell isolation and pictures were taken with 2 different lasers (UV laser providing excitation at $\sim 350 \mathrm{~nm}$ and another at $\sim 488 \mathrm{~nm}$ ) using a PALM-STORM NIKON Microscope (CIQLE). Then, the microplate was back in the C1 system where lysis, reverse-transcription and preamplification was performed. Primers have been previously described [21]. cDNA were loaded in a classic 96 well plate and conserved at $-20{ }^{\circ} \mathrm{C}$ until the RTqPCR.

- Biomark real-time PCR quantification of cDNA were performed using EvaGreen following the Fluidigm user guide available on their website. Each condition was loaded in parallel in the same microfluidicbased chip to avoid chip-to-chip technical variability. An IFC Controller HX performed the load of cDNA samples and primers from the inlets into the chip. The Biomark HD analyzed the chip according to the GE $96 \times 96$ PCR + Melt v2.pcl program. RNA spikes were used as positive control to validate the RT-qPCR experiment. From this outlet, the analysis software generated cycle of quantification values $\left(C_{q}\right)$ for each reaction.

\section{Image J analysis}

Each image corresponding at each lasers used were analyzed following a previously described procedure [31]. We visually confirmed the capture for each well and extracted automatically morphological information using ImageJ. After checking that all cells were detected by the software, we run the measurement of cell area (CFSE), nucleus area and intensity (Hoechst). The cell-volume (2) was then calculated from area measurements (1) using these following formulae:

$$
\begin{aligned}
& r=\sqrt{\frac{S}{\pi}} \\
& V=\frac{4}{3} \times \pi \times r^{3}
\end{aligned}
$$

with $\mathrm{r}$ the radius of cell, $\mathrm{S}$ the area and $\mathrm{V}$ the cell volume in $\mu \mathrm{m}^{3}$.

\section{Analysis of gene expression}

For population RT-qPCR analysis, ratios of gene expression variation between conditions were calculated following this following formulae [32]. Because of its low variability between all conditions, HnRNP was used as referential gene in these analyses. 
For single-cell RT-qPCR, raw $C_{q}$ data was then computed using $R$ [33] via a specific script that was previously described [21]. Some genes were excluded from analyses due to the quality control during the RTqPCR. The output file comprising absolute values of mRNA was used as a template for all following analysis. Statistical nonparametric tests were performed: correlations between gene expression and cell morphological parameters were performed using spearman tests. Wilcoxon tests were used to compare gene expression between stained and unstained conditions. Each time, Bonferroni correction was applied to p-values for the use of multiple tests.

\section{PCA}

PCAs were performed using ade4 package [34]. PCA was centered (mean substraction) and normalized (dividing by the standard deviation). PCA was displayed according to $\mathrm{PC} 1$ and $\mathrm{PC} 2$, which are the first and second axis of the PCA respectively.

\section{Results}

\section{Cellular morphological automatic measuring}

We choose the two low toxic fluorescent dyes, CFSE and Hoechst 33342 that stably incorporates into cells. In this study, CFSE was used as a cell area marker in tandem with Hoechst 33342 [35] as a nuclear marker. The use of two different lasers allowed revealing each staining (Fig. 1a, b) merged in Fig. 1c. It allowed us to automatically measure morphological cell parameters and inferred volumes.

We can observe that the cell volume is very poorly correlated with the nucleus volume (Fig. 2a). Therefore cell size by itself does not seem to be a good proxy for determining cell cycle position probably because it integrated other unknown parameters. Both cell and nucleus volume density distributions confirm that cell size spans a much larger range than the nucleus size which displays the classical 2n/4n distribution (Fig. 2b). Nuclear-volume was clearly more correlated with Hoechst fluorescence intensity than cell-volume (Fig. 2a, c). The nucleus volume can therefore be considered as a good indicator for the position of the cell in the cell cycle. Furthermore it should be noted that volume is a purely geometrical object that is not influenced by the laser bleaching, as Hoechst fluorescence intensity parameter.

We therefore described a double-staining procedure compatible with microscopy associated at the $\mathrm{C} 1$ system to measure, for each cell, their size and cell cycle state independently.

\section{Staining effect}

First, we assessed the influence of the double-staining procedure on gene expression at the population level by performing RT-qPCR on 5 selected genes known to be involved in erythroid differentiation or metabolism. The relative value of these gene expressions did not change significantly compared to unstained cells (Fig. 3a). These results suggested that cell and nucleus staining had no major influence on T2EC mean gene expression.

We then needed to discard possible modifications visible only at the individual-cell level. Therefore we performed high-throughput RT-qPCR on single cells using 77 genes that cover various functions as metabolism, differentiation process and proliferation [21]. We compared 30 single stained cells and 47 single unstained cells in the same microchip. Data was analyzed using a PCA-based dimensionality reduction algorithm (Fig. $3 \mathrm{~b}$ ) as well as Wilcoxon signed-rank tests (see Additional file 1: Table S1). The PCA does not show any separation between both conditions (PC1 and PC2 explained less than 12\% of the variability), and the statistical analysis shows that no gene was significantly varying between the two
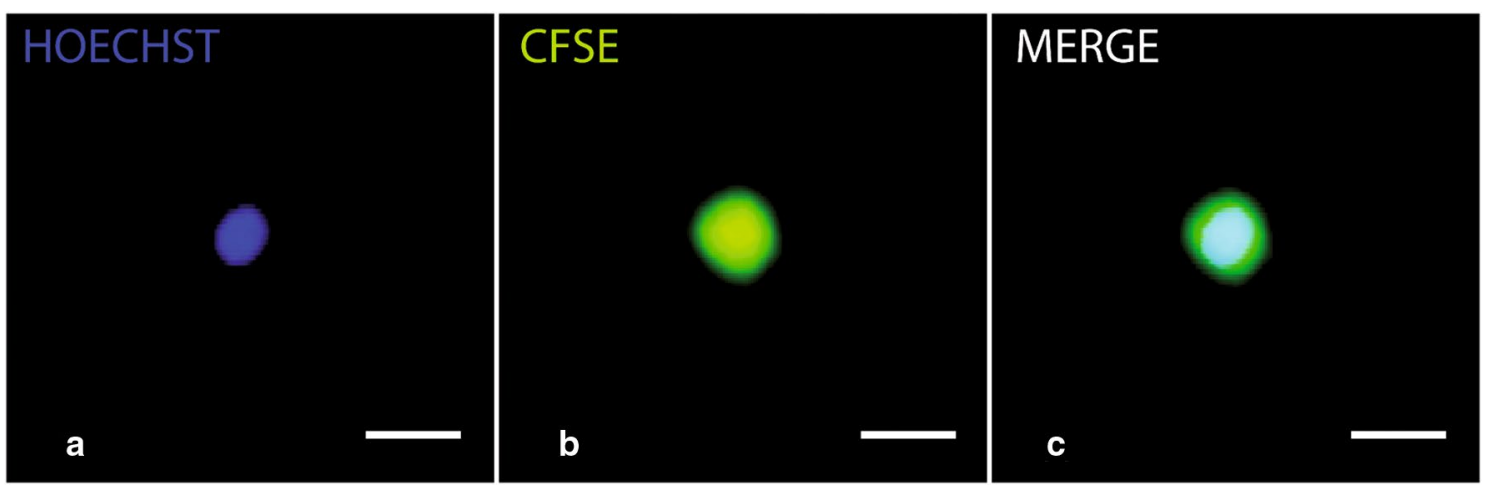

Fig. 1 CFSE/Hoechst double staining is compatible with C1 technology. Typical labeling of T2EC nucleus (a) and cytoplasm/membrane (b) stained by Hoechst 33342 and CFSE respectively. c Merged image of $\mathbf{a}, \mathbf{b}$. Cells were isolated with the C1 system and observed using a Nikon microscope with 2 different lasers. The scale bar represents $10 \mu \mathrm{M}$ 

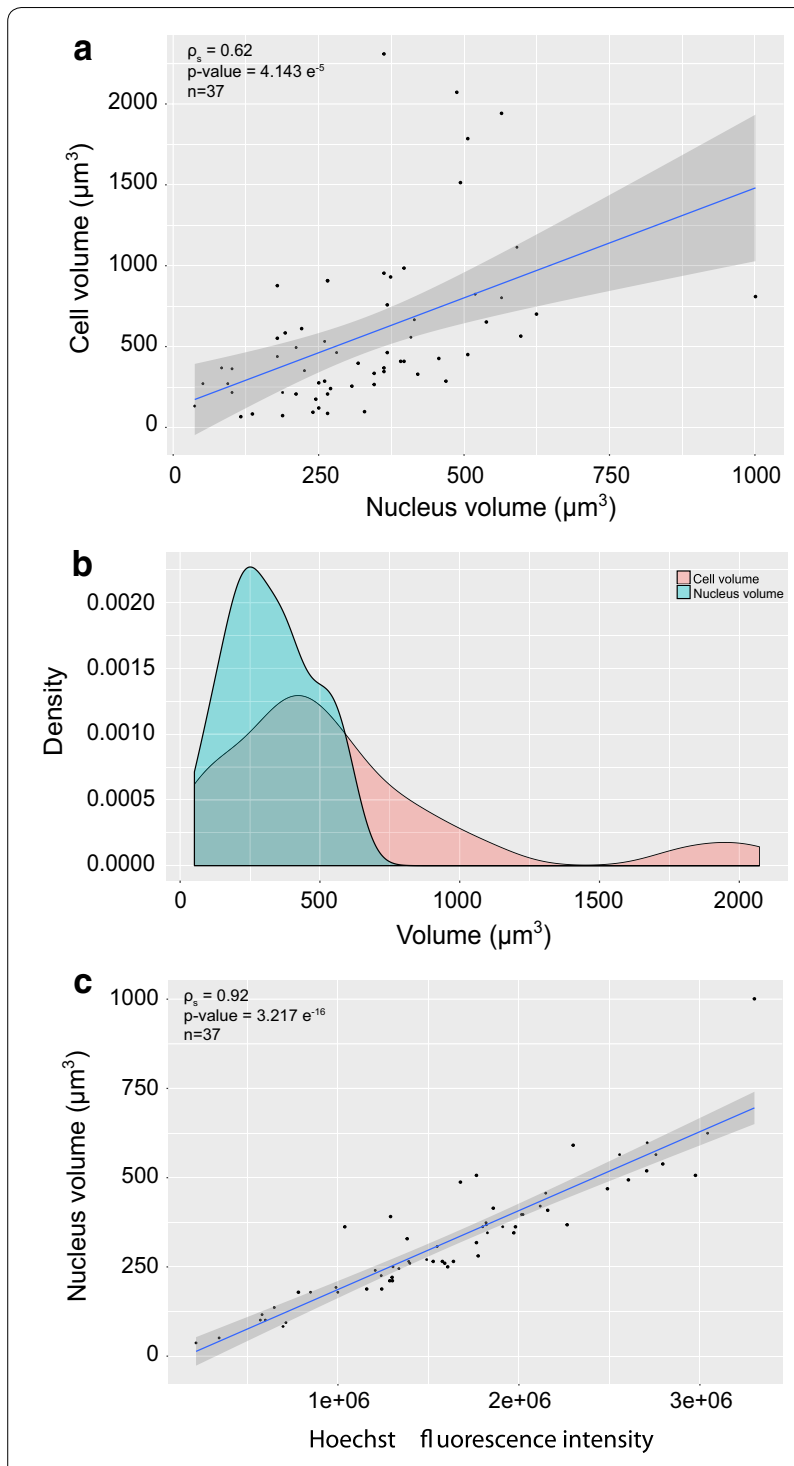

Fig. 2 Analysis of cell and nucleus size measurements. a Scatter plot showing the relation between cell volume and nucleus volume. Each point represents a cell. Spearman correlation test was performed, the result of which is displayed in the left upper corner. b Distribution of cell volumes (red curve) and nucleus volumes (blue curve). c Scatter plot showing the relation between Hoechst fluorescence intensity and nucleus volume. Each point represents a cell. Spearman correlation test was performed, the result of which is displayed in the left upper corner

conditions. These results therefore show that the staining did not affect the expression of these 77 genes in T2EC even when examined at the single-cell level.

Finally as an application example for our doublestaining approach, we investigated the influence of cell cycle and cell size on cell-to-cell variability among our gene expressions using the coupling of labeling and gene expression measurements at the single-cell level.

\section{Cell morphological impact on T2EC gene expression}

For each single cell, we measured the size, the position in the cell cycle and the mRNA amount. Among 69 genes analyzed (retained in this study for technical quality control), none presented a significant spearman correlation between its expression level among single cell volumes or cell cycle: all p-values were above the $5 \%$ threshold. These results confirmed that neither cell size nor the position in cell cycle were relevant parameters in explaining the cell-to-cell variations observed for 69 genes examined. This information is important for stochastic single-cell-based gene expression analysis, for which these morphological parameters can be excluded of the potential sources of variability between cells.

\section{Conclusion}

We performed a non-cytotoxic CFSE/Hoechst doublestaining compatible with the $\mathrm{C} 1$ system. This approach allowed automatic identification and measure of morphological parameters. It can be used to measure the influence of cell cycle and cell size on single-cell gene expression analysis without any potential misleading cell state effects induced by cell cycle synchronization methods. It could be also represent an alternative method to avoid artificial cell sorting according to their size or their cell cycle phase, which could be interesting for low amount of cells. This is equivalent to the recently described technique using flow cytometry [36], but applicable in the $\mathrm{C} 1$ system. As an alternative, it has recently been described that predefined gene combination could be used a posteriori [37]. Unfortunately, the best combinations seems to be cell type dependent, making it potentially limited [38].

We then used the Biomark system to perform gene expression quantification. We showed that the double staining did not impact gene expression in our cells. Moreover, by measuring the influence of cell cycle and cell size on the expression level of 69 genes, our results support our previous claim that cell cycle and cell size have a negligible influence on gene expression variability in certain settings [21]. This is in line with the recent demonstration that the cell cycle explains only a very small amount $(5-17 \%)$ of gene expression variability $[18$, 20].

\section{Limitations}

In this study, the main limitation was the optimization of cell capture in the $\mathrm{C} 1$ microchip. We obtained a maximum of $65 \%$ of capture whereas with other cells, this percent raise up to $95 \%$. Numerous parameters were involved and have to be optimized in order to obtain more individual cells per microchip. 

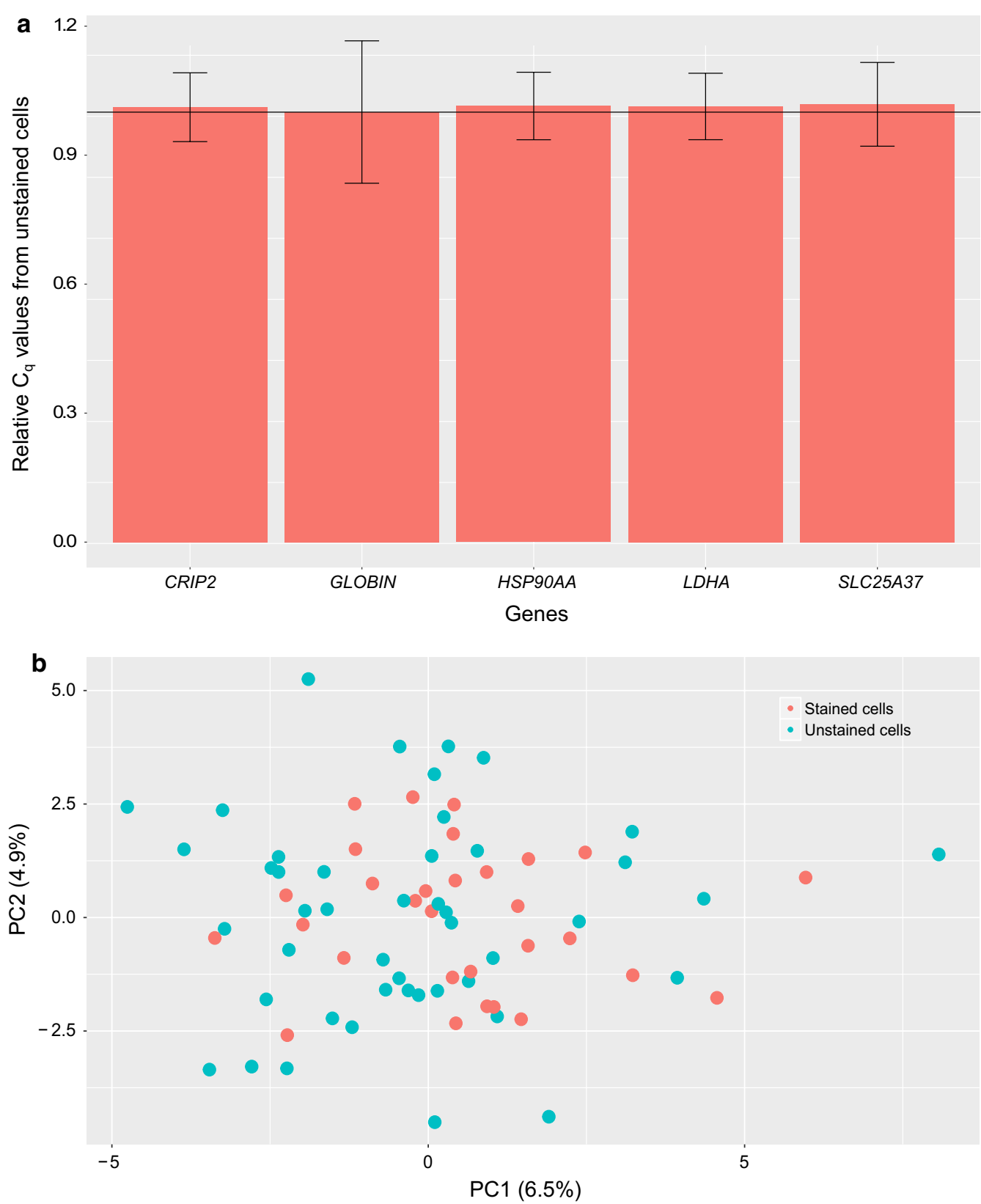

Fig. 3 Analysis of the influence of the staining procedure on gene expression. a Real-time PCR gene expression analysis of stained and unstained cells. Total RNA was extracted from T2EC cells stained or not. Reverse transcription and real-time PCR analyses, with specific primers [21], were performed to quantify the amount of GLOBIN ( $\beta$-GLOBIN), SLC (SLC25A37), HSP (HSP90AA1), CRIP2 and LDHA mRNA ( $C_{q}$ for cycle of quantification). The fold variations represented here correspond to the ratio of mRNA of staining cells compared to unstained cells. The black line corresponds to the null variation between the two conditions. The vertical bars represent the standard error of the mean value $(n=3)$. b Principal Component Analysis of single cell expression data acquired on stained or unstained cells. Projection of 77 T2EC single-cell stained or not onto PC1 and PC2 results in a cloud of points without any clear separation. Percentages shown are the percentage of variance explained by each component 


\section{Additional file}

\section{Additional file 1: Table S1. Statistical analysis of gene expression} according to the stained or the unstained condition. Statistical tests (Wilcoxon) were performed for each gene between their expression in stained and unstained condition. A Bonferroni correction was applied in p-values for multiple tests.

\section{Abbreviations}

(RT-q)PCR: reverse transcription quantitative polymerase chain reaction; T2EC: TGF-a/TGF- $\beta$-induced erythrocytic cells; (c)DNA: complementary deoxyribonucleic acid; (m)RNA: messenger ribonucleic acid; CFSE: carboxyfluorescein diacetate succinimidyl ester; PBS: phosphate-buffered saline; HnRNP: heterogeneous nuclear ribonucleoprotein; GE: gene expression; PCA: Principal Component Analysis; PC1: first principal component; PC2: second principal component.

\section{Authors' contributions}

AG designed and performed experiments and drafted the manuscript. ARdesigned and performed experiments. OG and SGG supervised the study.All the authors reviewed the manuscript. All authors read and approved thefinal manuscript

\section{Author details}

${ }^{1}$ Laboratoire de biologie et modélisation de la cellule. LBMC-Ecole Normale Supérieure-Lyon, Université Claude Bernard Lyon 1, Institut National de la Santé et de la Recherche Médicale: U1210-Ecole Normale Supérieure de Lyon, Centre National de la Recherche Scientifique: UMR5239, 46 Allée d'Italie, 69007 Lyon, France. ${ }^{2}$ Inria Dracula, 69100 Villeurbanne, France.

\section{Acknowledgements}

We thank ProfileXpert and "Plateforme d'imagerie CIQLE" (Genomique \& Microgenomique Unit, Universite Lyon 1, SFR Sante LYON-EST, UCBL-INSERM US 7-CNRS UMS 3453) for the use of C1 system and imagery.

\section{Competing interests}

The authors declare that they have no competing interests.

\section{Availability of data and materials}

The data set regarding the simultaneous measurement of gene expression,cell volume and nucleus volume is available at: https://osfio/ $8 \times 5 \mathrm{n} 7 /$.

\section{Consent for publication}

Not applicable.

\section{Ethics approval and consent to participate}

Not applicable.

\section{Funding}

This work was supported by funding from the French agency ANR (ICEBERG; ANR-IABI-3096) and La Ligue Contre le Cancer (Comite de Haute Savoie).

\section{Publisher's Note}

Springer Nature remains neutral with regard to jurisdictional claims in published maps and institutional affiliations.

Received: 23 November 2017 Accepted: 23 January 2018

Published online: 01 February 2018

\section{References}

1. Lyon MF. Gene action in the X-chromosome of the mouse (Mus musculus L.). Nature. 1961;190:372-3.

2. Spudich JL, Koshland DE. Non-genetic individuality: chance in the single cell. Nature. 1976;262(5568):467-71.
3. Raj A, Peskin CS, Tranchina D, Vargas DY, Tyagi S. Stochastic mRNA synthesis in mammalian cells. PLoS Biol. 2006:4(10):309.

4. Coulon A, Gandrillon O, Beslon G. On the spontaneous stochastic dynamics of a single gene: complexity of the molecular interplay at the promoter. BMC Syst Biol. 2010;4(4):2.

5. Gandrillon O, Kolesnik-Antoine D, Kupiec JJ, Beslon G. Chance at the heart of the cell. Prog Biophys Mol Biol. 2012;110:1-4.

6. Junker JP, van Oudenaarden A. Every cell is special: genome-wide studies add a new dimension to single-cell biology. Cell. 2014;157(1):8-11.

7. Swain PS, Elowitz MB, Siggia ED. Intrinsic and extrinsic contributions to stochasticity in gene expression. Proc Natl Acad Sci USA. 2002;99(20):12795-800

8. Elowitz MB, Levine AJ, Siggia ED. Stochastic gene expression in a single cell. Science. 2002;297(5584):1183-6.

9. Raser JM, O'Shea EK. Noise in gene expression: origins, consequences, and control. Science. 2005:309(5743):2010-3.

10. Morelli MJ, Allen RJ, Wolde PR. Effects of macromolecular crowding on genetic networks. Biophys J. 2011;101(12):2882-91.

11. Komorowski M, Miekisz J, Stumpf MP. Decomposing noise in biochemica signaling systems highlights the role of protein degradation. Biophys $\mathrm{J}$. 2013;104(8):1783-93.

12. Singh A. Cell-cycle control of developmentally regulated transcription factors accounts for heterogeneity in human pluripotent cells. Stem Cell Rep. 2013;1:532-44.

13. Padovan-Merhar O, Nair GP, Biaesch AG, Mayer A, Scarfone S, Foley SW, Wu AR, Churchman LS, Singh A, Raj A. Single mammalian cells compensate for differences in cellular volume and dna copy number through independent global transcriptional mechanisms. Mol Cell. 2015:58(2):339-52. https://doi.org/10.1016/j.molcel.2015.03.005.p40.

14. Buettner F, Natarajan KN, Casale FP, Proserpio V, Scialdone A, Theis FJ, Teichmann SA, Marioni JC, Stegle O. Computational analysis of cell-tocell heterogeneity in single-cell RNA-sequencing data reveals hidden subpopulations of cells. Nat Biotechnol. 2015:33(2):155-60. https://doi. org/10.1038/nbt.3102.p40.

15. Kimmerling RJ, Lee Szeto G, Li JW, Genshaft AS, Kazer SW, Payer KR, de Riba Borrajo J, Blainey PC, Irvine DJ, Shalek AK, Manalis SR. A microfluidic platform enabling single-cell RNA-seq of multigenerational lineages. Nat Commun. 2016;7:10220.

16. Newman JR, Ghaemmaghami S, Ihmels J, Breslow DK, Noble M, DeRisi $J$ L, Weissman JS. Single-cell proteomic analysis of S. cerevisiae reveals the architecture of biological noise. Nature. 2006;441(7095):840-6.

17. Loewer A, Lahav G. We are all individuals: causes and consequences of non-genetic heterogeneity in mammalian cells. Curr Opin Genet Dev. 2011:21(6):753-8

18. McDavid A, Dennis L, Danaher P, Finak G, Krouse M, Wang A, Webster P, Beechem J, Gottardo R. Modeling bi-modality improves characterization of cell cycle on gene expression in single cells. PLoS Comput Biol. 2014;10(7):1003696.

19. Chang HH, Hemberg M, Barahona M, Ingber DE, Huang S. Transcriptomewide noise controls lineage choice in mammalian progenitor cells. Nature. 2008:453(7194):544-7.

20. Klein AM, Mazutis L, Akartuna I, Tallapragada N, Veres A, Li V, Peshkin L, Weitz DA, Kirschner MW. Droplet barcoding for single-cell transcriptomics applied to embryonic stem cells. Cell. 2015;161(5):1187-201. https://doi org/10.1016/j.cell.2015.04.044.p40.

21. Richard A, Boullu L, Herbach U, Bonnafoux A, Morin V, Vallin E, Guillemin A, Papili Gao N, Gunawan R, Cosette J, Arnaud O, Kupiec JJ, Espinasse T, Gonin-Giraud S, Gandrillon O. Single-cell-based analysis highlights a surge in cell-to-cell molecular variability preceding irreversible commitment in a differentiation process. PLoS Biol. 2016;14(12):1002585.

22. Thattai $M$, van Oudenaarden A. Stochastic gene expression in fluctuating environments. Genetics. 2004;167(1):523-30. 0016-6731 (Print) Journal Article Research Support, Non-U.S. Gov't Research Support, U.S. Gov't, Non-P.H.S.

23. Weinberger LS, Burnett JC, Toettcher JE, Arkin AP, Schaffer DV. Stochastic gene expression in a lentiviral positive-feedback loop: HIV-1 tat fluctuations drive phenotypic diversity. Cell. 2005;122(2):169-82.

24. Cagatay T, Turcotte M, Elowitz MB, Garcia-Ojalvo J, Suel GM. Architecturedependent noise discriminates functionally analogous differentiation circuits. Cell. 2009;139(3):512-22. https://doi.org/10.1016/j.cell.2009.07.046. p39. 
25. Mojtahedi M, Skupin A, Zhou J, Castaño IG, Leong-Quong RYY, Chang H, Giuliani A, Huang S. Cell fate-decision as high-dimensional critical state transition. BioRvix. 2016. https://doi.org/10.1101/041541.

26. Sakaue-Sawano A, Miyawaki A. Visualizing spatiotemporal dynamics of multicellular cell-cycle progressions with fucci technology. Cold Spring Harb Protoc. 2014;132(3):487-498. https://doi.org/10.1016/j. cell.2007.12.033.

27. Scialdone A, Natarajan KN, Saraiva LR, Proserpio V, Teichmann SA, Stegle O, Marioni JC, Buettner F. Computational assignment of cell-cycle stage from single-cell transcriptome data. Methods. 2015;85:54-61. https://doi. org/10.1016/j.ymeth.2015.06.021.p40.

28. Vallejos CA, Marioni JC, Richardson S. Basics: Bayesian analysis of singlecell sequencing data. PLoS Comput Biol. 2015;11(6):1004333. https://doi. org/10.1371/journal.pcbi.1004333.p40.

29. Bruce A, Alexander J, Julian L, Martin R, Keith R, Peter W. Molecular biology of the cell. 4th edn. 2002.

30. Gandrillon O, Schmidt U, Beug H, Samarut J. TGF-beta cooperates with TGF-alpha to induce the self-renewal of normal erythrocytic progenitors: evidence for an autocrine mechanism. Embo J. 1999:18(10):2764-81. 0261-4189 Journal Article

31. Grishagin IV. Automatic cell counting with ImageJ. Anal Biochem. 2015;473:63-5.
32. Bresson C, Keime C, Faure C, Letrillard Y, Barbado M, Sanfilippo S, Benhra N, Gandrillon O, Gonin-Giraud S. Large-scale analysis by SAGE reveals new mechanisms of v-erbA oncogene action. BMC Genomics. 2007;8:390.

33. Team RDC. R: a language and environment for statistical computing. Vienna, Austria. ISBN 3-900051-07-0, http://www.R-project.org. 2008.

34. Dray $S$, Dufour AB. The ade4 package: implementing the duality diagram for ecologists. J Stat Softw. 2007;22:1-20.

35. Johansson L, Sohn D, Thorberg SO, Jackson DM, Kelder D, Larsson LG, Renyi L, Ross SB, Wallsten C, Eriksson H, Hu PS, Jerning E, Mohell N, Westlind-Danielsson A. The pharmacological characterization of a nove selective 5-hydroxytryptamine1a receptor antagonist, NAD-299. J Pharmacol Exp Ther. 1997;283(1):216-25.

36. Blasi T, Hennig H, Summers HD, Theis FJ, Cerveira J, Patterson JO, Davies D, Filby A, Carpenter AE, Rees P. Label-free cell cycle analysis for highthroughput imaging flow cytometry. Nat Commun. 2016;7:10256.

37. Liu Z, Lou H, Xie K, Wang H, Chen N, Aparicio OM, Zhang MQ, Jiang R, Chen T. Reconstructing cell cycle pseudo time-series via single-cell transcriptome data. Nat Commun. 2017;8(1):22.

38. Dolatabadi S, Candia J, Akrap N, Vannas C, Tesan Tomic T, Losert W, Landberg G, Aman P, Stahlberg A. Cell cycle and cell size dependent gene expression reveals distinct subpopulations at single-cell level. Front Genet. 2017;8:1.

\section{Submit your next manuscript to BioMed Central and we will help you at every step:}

- We accept pre-submission inquiries

- Our selector tool helps you to find the most relevant journal

- We provide round the clock customer support

- Convenient online submission

- Thorough peer review

- Inclusion in PubMed and all major indexing services

- Maximum visibility for your research

Submit your manuscript at www.biomedcentral.com/submit 